\title{
Cost-Effective Optoelectronic Packages Using Powder Metallurgy
}

\author{
Chun-Ting Lin, Bi-Shiou Chiou, and Sien Chi
}

\begin{abstract}
In this paper, we propose powder metallurgy for optoelectronic packages in order to reduce the cost of laser packages. Conventional die compaction (DC) and metal injection molding (MIM) are used for the shaping of powder metallurgy. The distinguishing types of inherent porosity in DC and MIM steels have their respective effects on the defect mechanisms of laser welding joints. For DC steel with $85 \%$ relative density and continuous porosity, the rising gas pressure pushes the molten metal out of the welding regions, resulting in weak and unstable welding joints. For MIM steel with more than $95 \%$ relative density, the laser power dominates the defect mechanisms, and the defect-free welding joints with optical spot size of $400 \mu \mathrm{m}$ can be attained by using laser power of less than $1.0 \mathrm{~kW}$. Although elimination of inherent porosity in MIM steel under optimum welding condition can give rise to additional postwelding-shift (PWS), it is still controlled to less than $2 \mu \mathrm{m}$, resulting in optical coupling loss of less than $15 \%$. The advantage of applicability of the MIM method to several materials makes it possible to employ SS316L, Kovar, and Invar, which have the characteristic of better property for laser welding but difficult machining, as the metal housing in low-cost lightwave communication system. Thus, using MIM Invar with low coefficient of thermal expansion can minimize the tracking error, which is an important issue for bidirectional and triple-directional optoelectronic packages. The reliability data demonstrate that the laser modules using MIM steel as construction housing are stable and reliable.
\end{abstract}

Index Terms-Bidirectional transmission, laser welds, metal injection molding, optoelectronic packages, powder metallurgy, triple-directional transmission.

\section{INTRODUCTION}

B ROADBAND communication accelerates the demand of fiber-to-the-home (FTTH) systems taking us into the future world of video phones, thousands of television channels, movies-on-demand, long distance learning, and threedimensional (3-D) online games. The successful introduction of low-cost bidirectional or even triple-directional optoelectronic

Manuscript received September 5, 2005; revised May 23, 2006. This work was supported by the National Science Council, Taiwan, R.O.C., under Contracts NSC 95-2752-E-009-009-PAE, NSC 94-2215-E-155-001, NSC 94-2215E-155-003, and NSC 94-2216-E-009-022.

C.-T. Lin is with the Department of Photonics and Institute of Electro-Optical Engineering, National Chiao Tung University, Hsinchu 300, Taiwan, R.O.C., (e-mail: jinting@ms94.url.com.tw).

B.-S. Chiou is with the Department of Electronics Engineering and Institute of Electronics, Innovative Packaging Research Center, National Chiao Tung University, Hsinchu 300, Taiwan, R.O.C. (e-mail: bschiou@mail.nctu.edu.tw).

$\mathrm{S}$. Chi is with the Department of Photonics and Institute of Electro-Optical Engineering, National Chiao Tung University, Hsinchu 300, Taiwan, R.O.C., and also with the Department of Electrical Engineering, Yuan Ze University, Chung-Li 320, Taiwan, R.O.C. (e-mail: schi@mail.nctu.edu.tw).

Digital Object Identifier 10.1109/JSTQE.2006.879530 modules is the key to the FTTH, and the primary contribution of the cost arises from packaging the laser. Submicrometeraccuracy alignments and strong joints for laser packages are essential to achieve high coupling efficiency and long-term stability. The laser welding technique is the best candidate to satisfy such criteria and offers lots of advantages, such as good long-term stability, high joint strength to welding size ratio, high-volume and high-speed production, submicrometeraccuracy fixing, no contact process, and good repeatability [1]-[6].

The laser packaging bodies are typically categorized into two types: box-type and cylindrical-type [1]. The box-type and cylindrical-type optoelectronic packages dominate highperformance lightwave communication systems and low-cost markets, respectively. The box-type package allows more space for a thermoelectric cooler and multiple components to achieve high speed, high power output, high reliability, and operation at constant temperature. The cylindrical-type package based on transistor outline (TO)-Can is used where the fabrication cost is important and the performance requirement is not so high. Recently, FTTH systems have delivered video, voice, and data to consumers on one fiber where $1310-\mathrm{nm}$ transmission is in one direction, and 1490- and/or 1550-nm transmissions are in the other direction, as shown in Fig. 1. These bidirectional and triple-directional data transmissions of FTTH systems require the transformation of cylindrical-type packages into box-type packages because more room is needed to accommodate more wavelength division multiplexing (WDM) filters and lenses. This transformation results in an increased number and cost of metal parts, which is contradictory to the low-cost market. In addition, machining accuracy of metal parts is very critical to the yield of the laser welding process. Although the conventional machining method of fabricating metal parts can make metal parts with box shape and accurate dimension, the cost is still too high. Although numerous studies on improving the performance of the box-type optoelectronic packages have been conducted recently [7]-[11], only limited information is available on how to design and fabricate high-yield, high-performance, and low-cost bidirectional or triple-directional optoelectronics packages.

In this paper, powder metallurgy is proposed as a costeffective method of fabricating metal parts. The major advantages of powder metallurgy originate from the ability to shape metal powders into the final desired form. The conventional shaping of powder metallurgy is die compaction (DC) performed by using both upper and lower punches that press metal powders into the die to form the desired shape [12]. The DC method involves less production cost and high accuracy, 


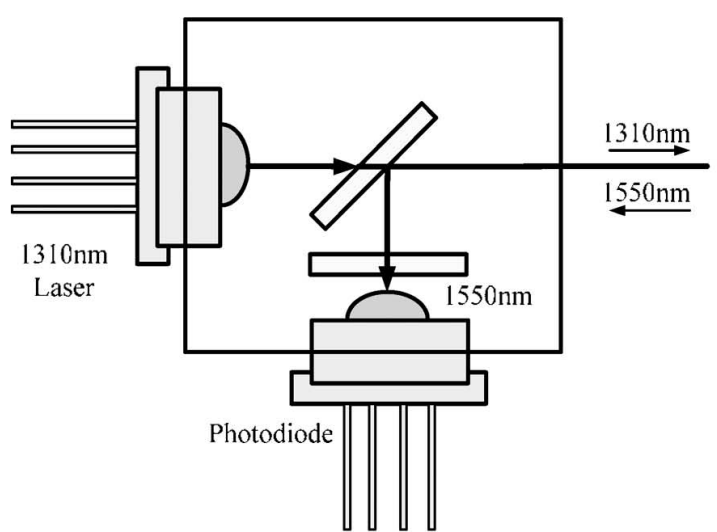

(a)

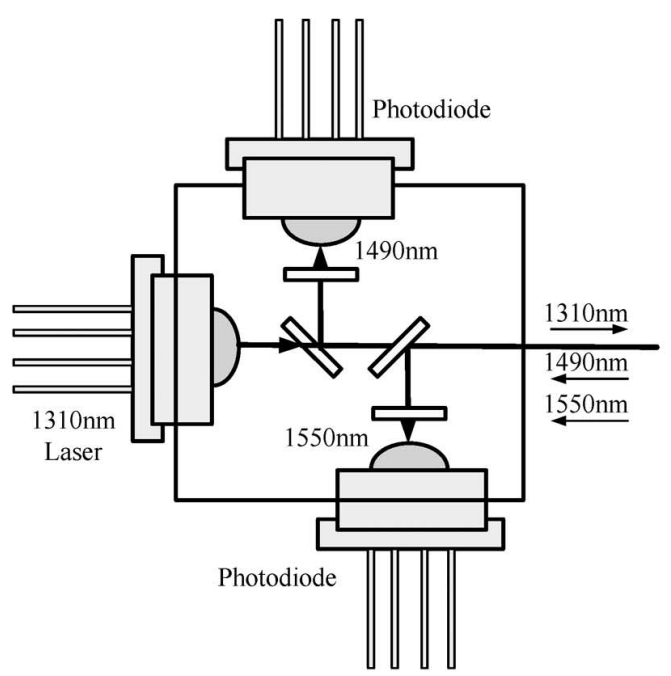

(b)

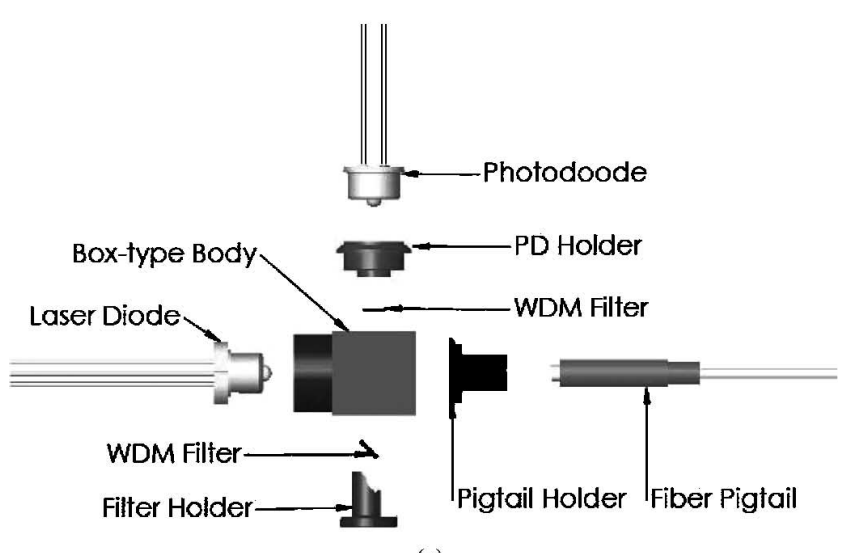

(c)

Fig. 1. Box-type packages allow more room for WDM filters, lenses, and the associated metal parts. (a) Illustration of bidirectional optoelectronic package. (b) Illustration of triple-directional optoelectronic package. (c) The components of bidirectional optoelectronic package.

but it also provides less shape complexity and less mechanical properties. Metal injection molding (MIM) is a relatively new shaping method [13]. Metal powders are mixed with organic binders to form a fluid mass and injected under pressure into a die of the desired shape. The shaping metal powders are then heated to remove the binder and are eventually sintered. Owing to the use of fine metal powders of less than $20 \mu \mathrm{m}$, the sintering shrinkages are large and final densities of more than $95 \%$ are attainable. In comparison with other shaping technologies, the MIM method overcomes the final density and shape limitations of the DC method and the costs of conventional machining. The MIM method offers five features: low production cost, shape complexity, tight tolerance, applicability to several materials, and high mechanical properties. The box-type body and other parts of bidirectional optoelectronic modules can be replaced with one MIM SS316L housing due to shape complexity, as shown in Fig. 1(c). Therefore, employing the MIM method not only reduces the number of metal parts but also greatly reduces the cost. However, the inherent porosity of the MIM and DC stainless steel cannot be avoided, and it has a great influence on defect formation of the welding joints such as cracks and holes resulting in the degradation of stability and additional postwelding-shift (PWS) [6].

In this paper, the weldability of MIM and DC stainless steel is investigated. The rest of the paper is organized as follows. Section II describes the laser welding system, material selection, and the package construction. The welding defect mechanisms of MIM and DC steel, optimum welding parameter, PWS measurement, and tracking error are discussed in Section III. The reliability data are presented in Section IV. A brief summary and conclusion are given in Section V.

\section{LASER WELDING SYSTEM AND EXPERIMENTAL PROCEDURES}

\section{A. Laser Welding System}

Fig. 2 shows the setup of the laser welding system used in this study. The system can be divided into three subsystems: alignment system, Nd:YAG laser system, and process controller system. The alignment system comprises four motion stages for four degrees of alignment $(x, y, z$, and $\theta)$ between the laser diode and optical fiber. Upper and lower toolings are mounted on the $x-/ y-/ \theta$-stages and the $z$-stage, respectively. The Nd:YAG laser system consists of pulsed Nd:YAG laser, fiber optical beamdelivery system, and the charge-coupled device (CCD) monitor. The main beam from laser cavity is separated into three beams by three partial mirrors with different reflection to achieve beam balance of less than 3\%. The three laser beams are delivered by a $600-\mu \mathrm{m}$ step-index optical fiber and then focused on the workpiece with the focal spot size that is $400 \mu \mathrm{m}$ in diameter. Each beam is precisely adjusted with an incident angle of $\left(45^{\circ} \pm 1^{\circ}\right)$ and positioned $120^{\circ}$ apart from each other. The simultaneous and equal laser energy delivery is designed to reduce PWS between the two welded parts because the solidificationshrinkage of three welding spots can compensate each other, resulting in minimizing misalignment shift. To reduce the metal oxidation during laser welding, nitrogen gas is used as the shield on the molten metal. The process controller consists of main computer, alignment motion controller, laser beam motion controller, LD driver, and optical power meter. Under such 


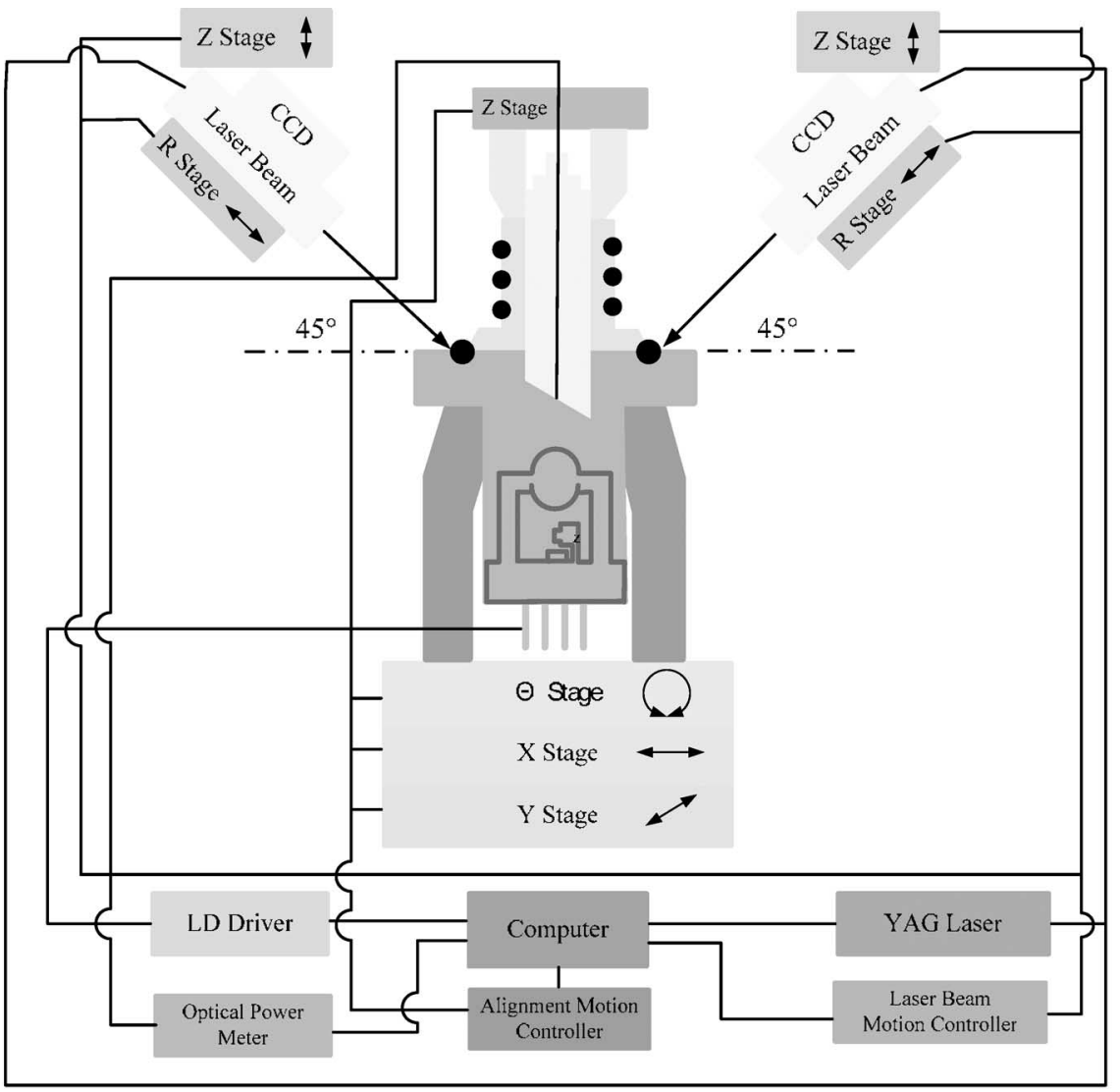

(a)

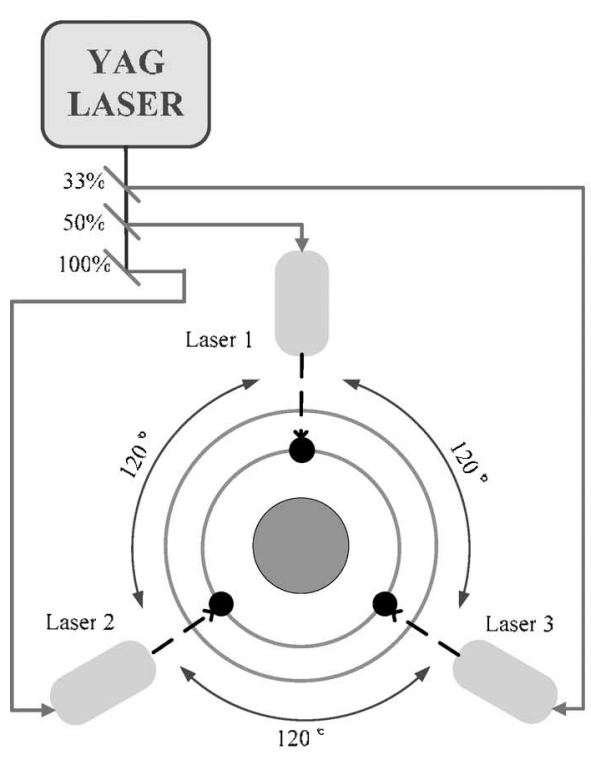

(b)

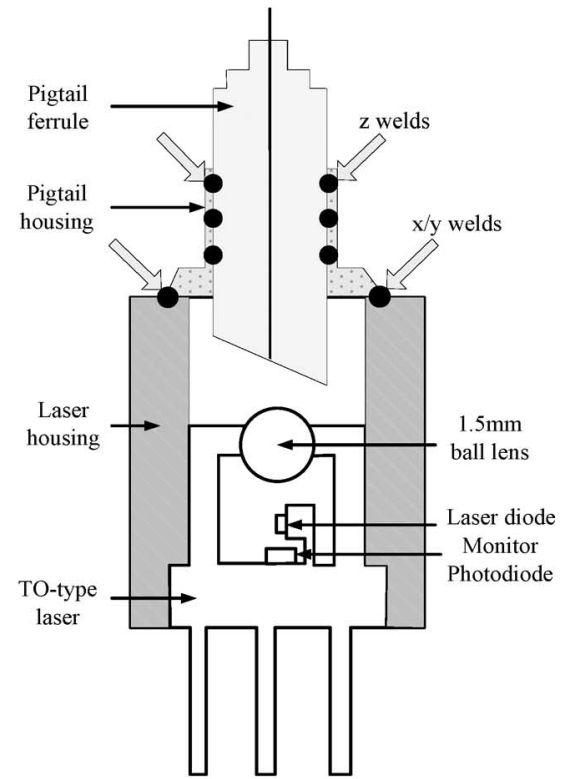

(c)

Fig. 2. (a), (b) Schematic diagram of the laser welding system. (c) Configuration of the cylindrical-type laser module. Arrows indicate the welding spots.

a setup, an automatic active alignment to achieve maximum optical coupling efficiency and a semiautomatic triggering of the laser on the accurate position of metal joint are attained.

The pulsed laser welding parameters, such as laser power, pulse duration, and pulse energy, directly affect the joint quality and need to be carefully controlled to give repeatable joints in the laser welding process. The pulse energy $E$ is calculated by $E=P \times T$, where $P$ and $T$ are laser power and pulse duration, respectively. High laser power and high pulse energy cause hole formation, cracks, and metal injection. In this paper, laser power and pulse duration are controlled and selected as $0.6-1.6 \mathrm{~kW}$ and $2-6 \mathrm{~ms}$, respectively. 


\section{B. Material Selection}

The choice of material has a great influence on the metallurgical compatibility of the metal with laser welding process. Stainless steel 304L (SS304L) and 316L (SS316L) with low carbon content show good laser weldability. SS304L with austenite texture offers good mechanical properties, corrosion/oxidation resistance, and relatively low cost. SS316L, which is an improved version of SS304L by the addition of molybdenum and a slightly high nickel content, provides better corrosion/creep resistance and higher mechanical strength, but the machining process of SS316L is more complicated than that of SS304L. One important issue of material selection for the reliability of optoelectronic packages is the stress caused by thermal expansion, resulting in alignment changes after instant laser welding or long-term stress release. Therefore, metal housing materials with low coefficient of thermal expansion (CTE) are required. Kovar and Invar with very low CTE, $5.1 \times 10^{-6}{ }^{\circ} \mathrm{C}$ and $1.5 \times 10^{-6}{ }^{\circ} \mathrm{C}$, respectively, have been frequently used as the metal housing for box-type optoelectronic packages in high-performance lightwave communication systems. The metal housings made of Invar and Kovar not only reduce stress and alignment changes after laser welding process but also provide better performance stability at varying ambient temperatures. In addition, Invar and Kovar used as the metal housings can minimize the fatigue stress and strain developed during thermal cycling associated with environmental exposure and device operation.

However, only SS304L has been widely used as the metal housing for cylindrical-type optoelectronic packages due to easy machining. High nickel contents of SS316L, Kovar, and Invar increase the difficulty of machining, resulting in raising the machining cost. Thus, the metal housings made of SS316L, Kovar, and Invar, which show better laser welding performance, are only employed in high-performance lightwave communication systems based on box-type optoelectronic packages, regardless of the cost issue. The advantages of applicability to several materials and the ability to shape metal powders into the final desired form from the MIM method make it possible to employ SS316L, Kovar, and Invar as the metal housing used in low-cost lightwave communication systems. In this study, DC SS316L, MIM SS316L, and MIM Invar are selected as housing materials to investigate the laser weldability.

\section{Laser Package Construction}

For simplicity, the cylindrical-type laser module based on TOCan laser diode and pigtail construction, as shown in Fig. 2(c), is employed. The laser module can be divided into two main parts: a laser part and a pigtail fiber part, which are assembled by laser welding with a pressure of $5 \mathrm{~kg}$ [6] and a total of six welding spots to ensure a strong bonding. The laser part consists of a 1310-nm TO-Can laser package with a built-in 1.5-mm ball lens and a laser housing made of MIM steel, which is used to replace the box-type body of bidirectional or triple-directional optoelectronic modules as shown in Fig. 1(c). MIM SS316L and MIM Invar are selected as the laser housing materials to investigate PWS, tracking error, and reliability. The TO-Can laser package is pressed into the laser housing by air-punch and bonded with thermal epoxy. The pressure-fix design with assistant thermal epoxy-bonding gives the advantage of a quick, easy, and reliable assembly. The pigtail fiber part consists of a SS304L pigtail ferrule, including an angle-polished ceramic and a single-mode fiber, and a pigtail housing made of SS304L fabricated by conventional machining. The pigtail ferrule and the pigtail housing are jointed by laser welding with a total of nine welding spots. To provide good contacts between two welded surfaces to ensure good joints without cracks caused by mismatch of two components, the accuracies of perpendicularity, parallelism, roughness, and flatness should be less than $50 \mu \mathrm{m}, 50 \mu \mathrm{m}, 0.1 \mathrm{Ra}$ (arithmetical mean roughness), and $10 \mu \mathrm{m}$, respectively.

\section{RESUltS AND DEFECT FORMATION MECHANISM}

\section{A. Microstructures of DC and MIM Steel}

The DC and MIM processes include powder mixing, molding, debinding, sintering, and surface treatment. Fig. 3 shows the microstructures of the final MIM SS316L, MIM Invar, and DC SS316L with $97 \%, 96 \%$, and $85 \%$ of the full density, respectively. The diameter of pores in MIM SS316L and MIM Invar ranges from 2 to $5 \mu \mathrm{m}$, and the pores are discontinuous and isolated by the matrix. However, the sizes of the pores in DC SS316L have wider distribution up to $10 \mu \mathrm{m}$, and the pores are continuous and cross-linked. These distinguishing types of pores have their respective effects on the defect mechanisms of laser welding joints, and this phenomenon will be discussed later.

\section{B. Defect Formation of Laser Welding Spots in MIM SS316L and DC SS316L}

The laser welding process involves pulsed laser energy focused on the small area, which is absorbed by the jointed materials. Highly focused energy causes a welding pool on an extremely localized area, and subsequently rapid cooling of the welding pool and the associated material shrinkage may give rise to welding defects. To ensure long-term stability of welding joints, metallurgical analysis has been extensively used to investigate inner defects of the laser welding spots and joints, such as porosity and cracks. Metallurgical analysis also provides penetration depth and welding width of the laser welding spot. The procedures of metallurgical analysis include specimen sectioning, mounting, grinding, polishing, chemical etching, and microstructural examination.

The pulsed laser welding spots with an incident angle of $45^{\circ}$ in MIM SS316L are shown in Fig. 4. Most of the inherent pores in the melting pool of welding spots disappear, but other defects, holes, arise when laser power is more than $1.2 \mathrm{~kW}$ with optical spot size of $400 \mu \mathrm{m}$. Among the pulsed laser welding parameters, the laser power dominates hole formation. When the laser power $P$ is $1.0 \mathrm{~kW}$ and the pulse duration $T$ ranges from 2 to $6 \mathrm{~ms}$, no hole formation is observed. While the energy of the welding spot shown in Fig. 4(f) is more than that of the welding spot shown in Fig. 4(c) and (d), no hole is formed in Fig. 4(f). The welding spots with two pulses of laser give full support to 


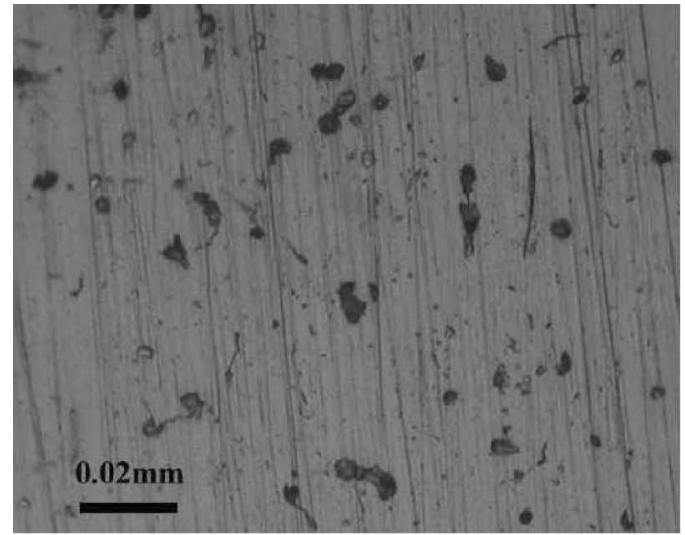

(a)

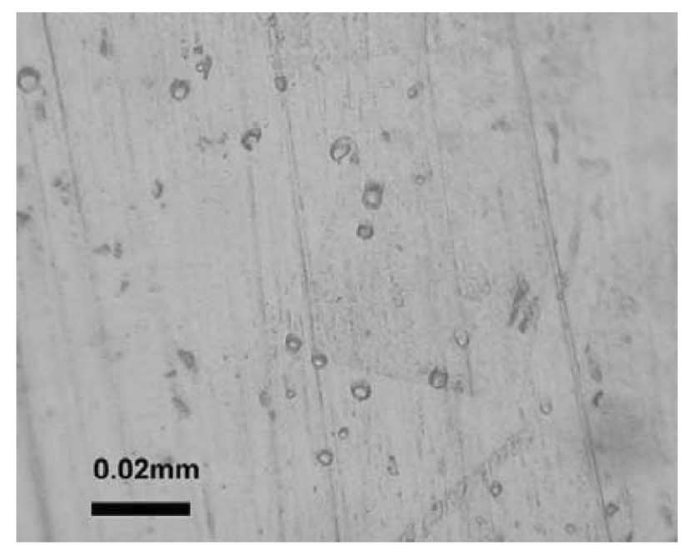

(b)

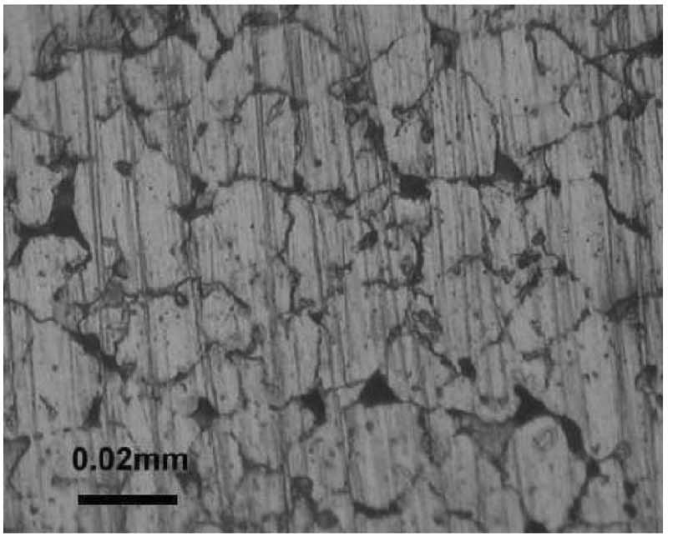

(c)

Fig. 3. Microstructures of MIM 316L, DC SS316L, and MIM Invar. (a) MIM SS316L with $97 \%$ of full density. (b) MIM Invar with $96 \%$ of full density. (c) DC SS316L with $85 \%$ of full density.

the above results. The power of the first pulsed laser is $1.0 \mathrm{~kW}$, when the defect-free welding spot is achieved, and that of the second pulsed laser is more than $1.2 \mathrm{~kW}$. The time between the two pulses of laser is $5 \mathrm{~s}$. Fig. 5 shows that the holes are observed and always occupy the tip of the welding pool where the first pulsed laser cannot reach. This observation confirms that the laser power is one of the most important parameters to dominate the defect mechanism of the pulsed laser welding process. The possible cause of hole formation is that the gas

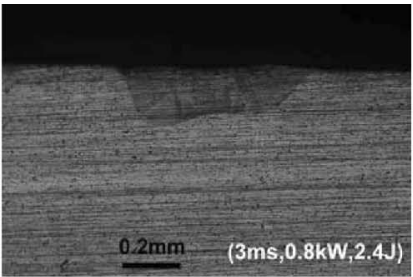

(a)

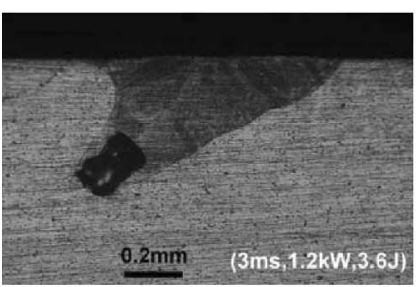

(c)

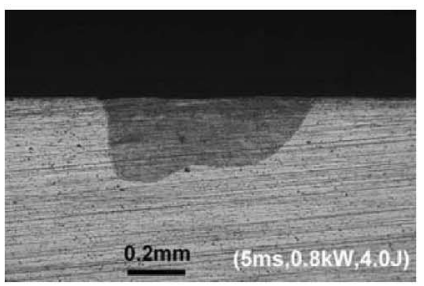

(e)

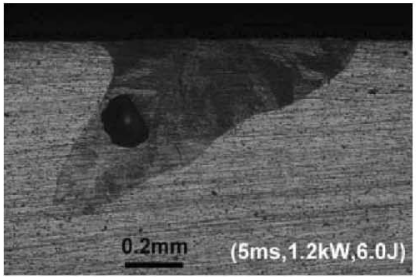

(g)

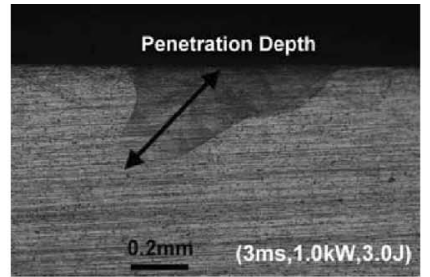

(b)

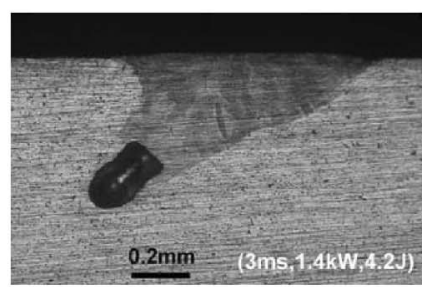

(d)

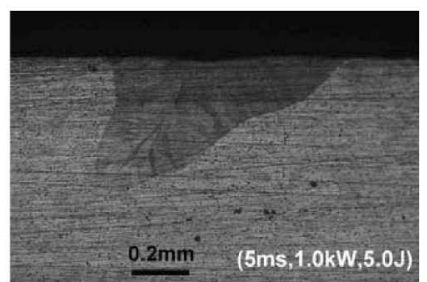

(f)

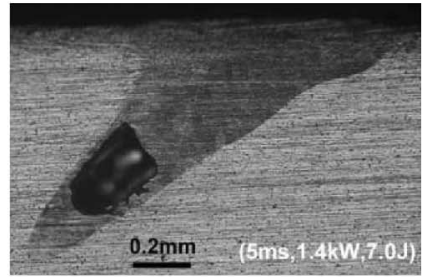

(h)
Fig. 4. Cross sections of the welding spots in the MIM SS316L with various welding conditions. Data in parentheses are pulse duration (millisecond), power (kilowatt), and laser energy (joule).

trapped in the inherent pores of MIM SS316L absorbs heat from molten steel to expand and subsequently nucleates and grows to form a hole in the welding spot. Because the laser beams have smooth Gaussian-like spatial extent in the cross section, the laser power is the maximum in the center of the optical axis with an incident angle of $45^{\circ}$. Thus, the holes always occupy the optical axis and are symmetrically aligned along it.

Fig. 6 shows the pulsed laser welding spots of DC SS316L with continuous and cross-linked type of porosity. The hole formation cannot be avoided even when the laser power is less than $1 \mathrm{~kW}$. More than one hole are observed and are found to be randomly situated in the welding pool. Besides, another defect, crack, is generated and is usually situated along the optical axis with an incident angle of $45^{\circ}$. The reason why the cracks occupy the optical axis is that the molten metal pool solidifies from the periphery toward the optical axis, and finally the crack is formed along the optical axis due to material shrinkage and high contents of inherent pores.

The penetration depth is measured in the direction of the laser beam with focused spot size of $400 \mu \mathrm{m}$, as shown in Fig. 4(b). 


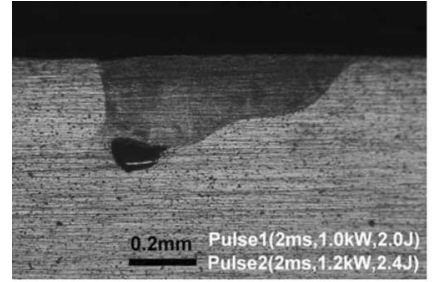

(a)

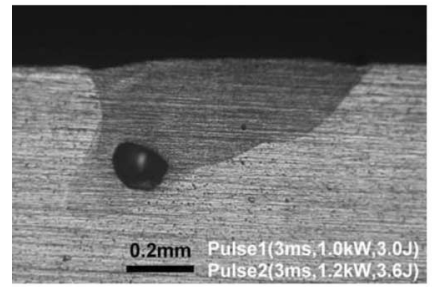

(c)

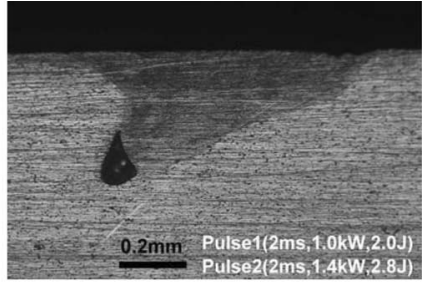

(b)

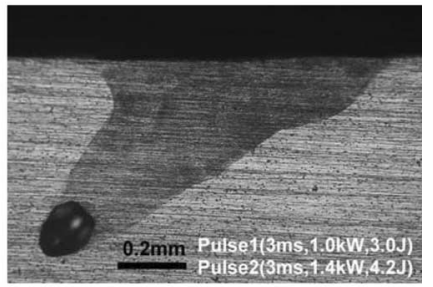

(d)
Fig. 5. Cross sections of the welding spots with two pulses of laser in the MIM SS316L. Data in parentheses are pulse duration (millisecond), power (kilowatt), and laser energy (joule).

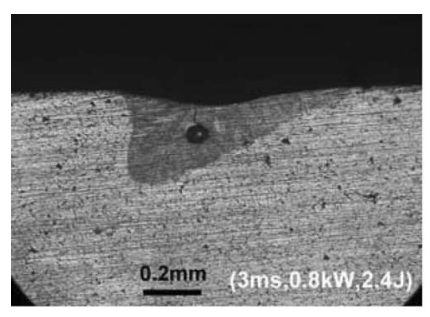

(a)

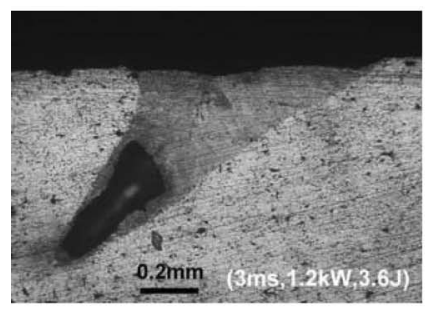

(c)

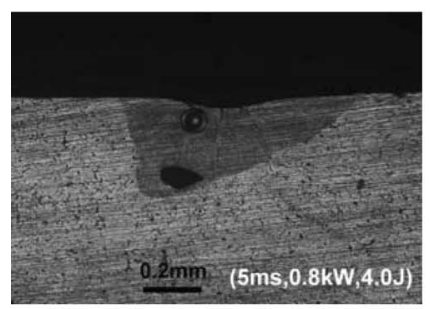

(e)

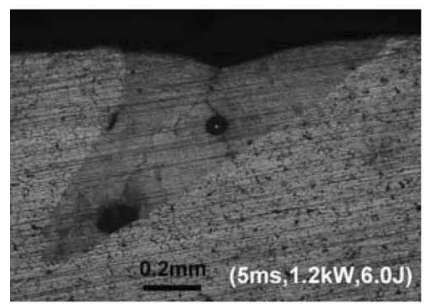

(g)

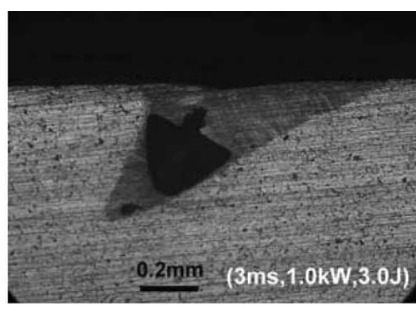

(b)

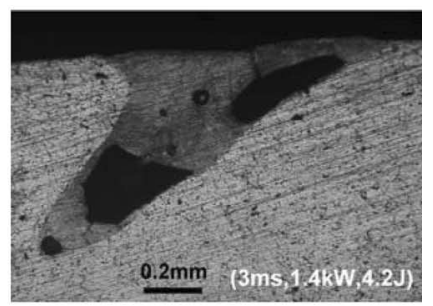

(d)

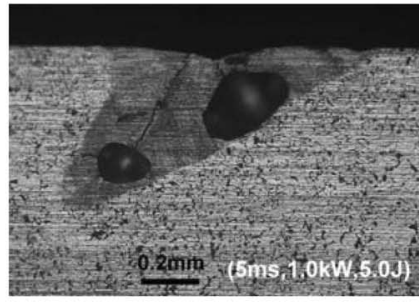

(f)

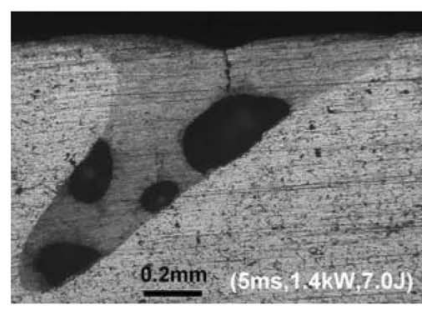

(h)
Fig. 6. Cross sections of the welding spots in the DC SS316L with various welding conditions. Data in parentheses are pulse duration (millisecond), power (kilowatt), and laser energy (joule).

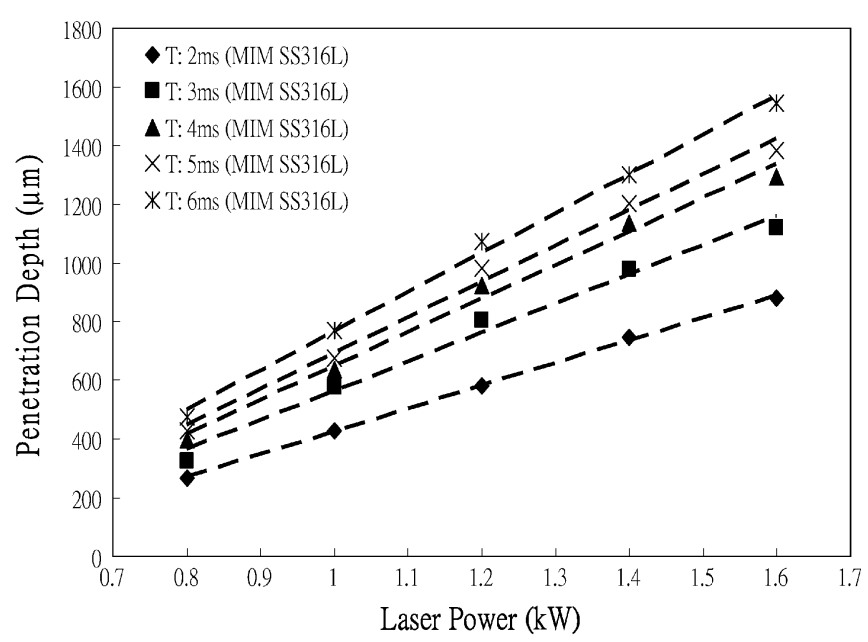

(a)

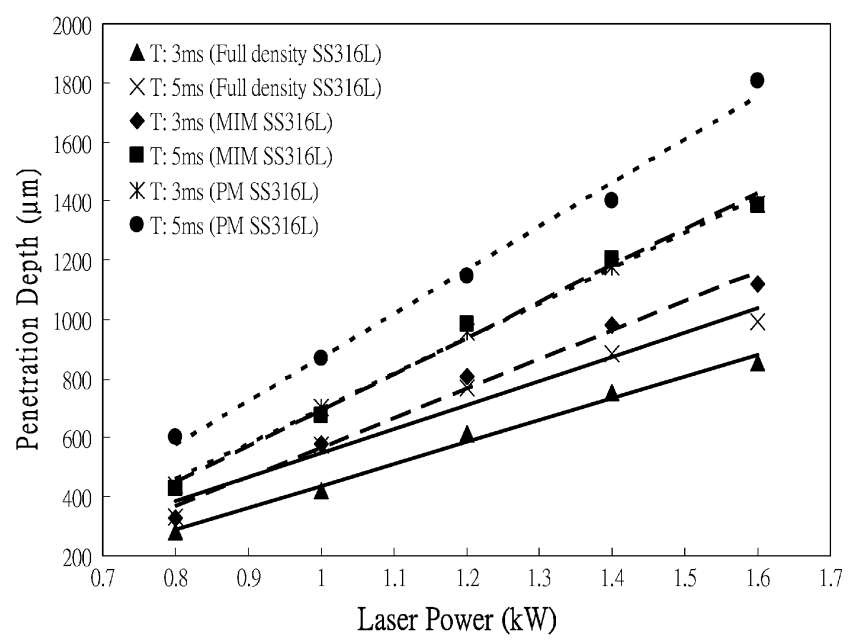

(b)

Fig. 7. Penetration depth of welding spots as a function of laser power with various pulse durations T. (a) MIM SS316L. (b) Full-density SS316L, MIM SS316, and DC SS316L.

Fig. 7(a) shows the penetration depths of the welding spots in MIM SS316L as a function of the laser power and pulse duration. The penetration depth increases linearly with an increase in the pulse duration at the fixed laser power and increases as the laser power increases at the fixed pulse duration. Fig. 7(b) shows the penetration depth of the welding spots with different relative densities of SS316L, i.e., $100 \%, 97 \%$, and $85 \%$. The penetration depth increases as the relative density of the specimen decreases.

\section{Defect Formation of MIM SS316L and DC SS316L Jointed With SS304}

The cross sections of the welding joints, MIM SS316L jointed with full-density SS304L (MIM316L/304L), are shown in Fig. 8. Similar to what was observed in the welding spots of MIM SS316L, most of the inherent pores disappear in the areas of welding joints, and the formation of holes is not observed as the laser power is below $1.0 \mathrm{~kW}$. Thus, the defect-free welding 


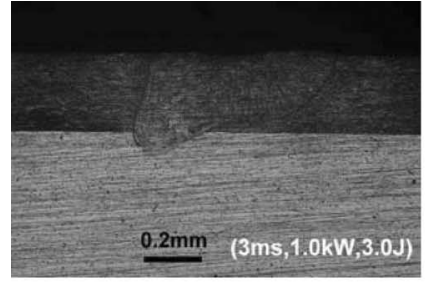

(a)

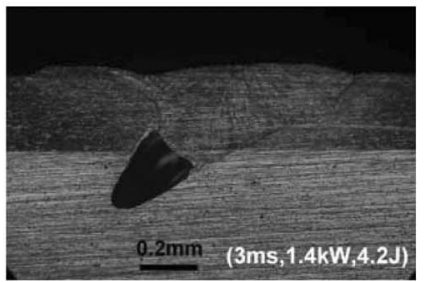

(c)

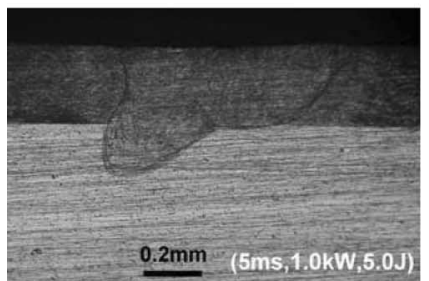

(e)

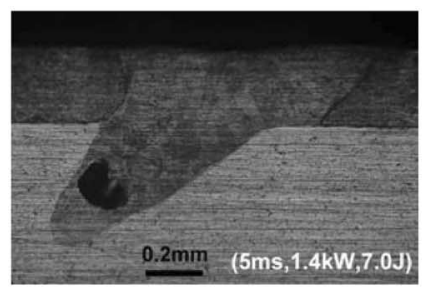

(g)

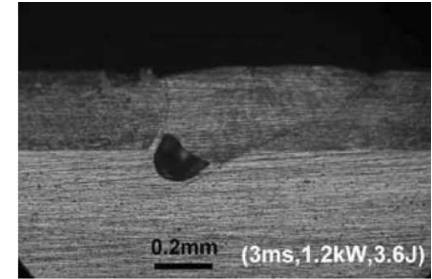

(b)

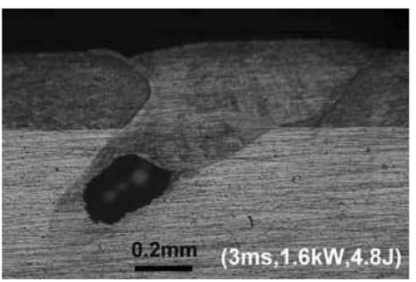

(d)

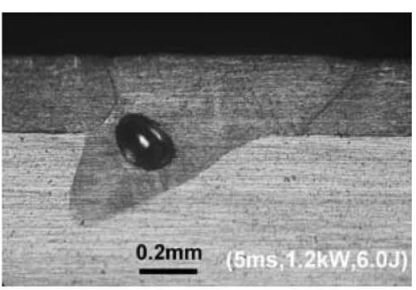

(f)

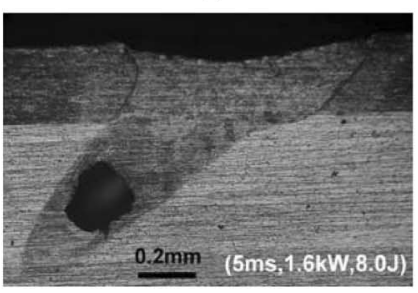

(h)
Fig. 8. Welding joints of MIM SS316L (bottom) and SS304L (top). Data in parentheses are pulse duration (millisecond), power (kilowatt), and laser energy (joule).

joints of MIM steel can be achieved by using the laser power of less than $1.0 \mathrm{~kW}$. However, for DC316L/SS304L joints, gas expansion of a serious nature gives rise to metal injection resulting in weak and unstable joints as shown in Fig. 9. In the welding spots of DC SS316L, most of the expanding gas can escape from the welding spot along the continuous porosity. As for DC316L/304L joints, fully dense SS304L blocks the expanding gas out of the welding region and the gas pressure raises to inject the melting steel out of the welding joints, resulting in weak and unstable welding joints. Therefore, DC steel with $85 \%$ relative density and continuous porosity cannot be adopted as the metal housing for the laser welding process.

\section{Selection of Optimum Welding Conditions}

The laser power is one of the most important parameters that dominate the defect mechanism of the laser welding process for optoelectronic packages. Besides, the welding geometries, such as lap joint, fillet joint, and lap-fillet joint, greatly affect the joint strength and the stability of the welding spot. To ensure long-term reliability of welding joints, the strengths of lap, fillet,

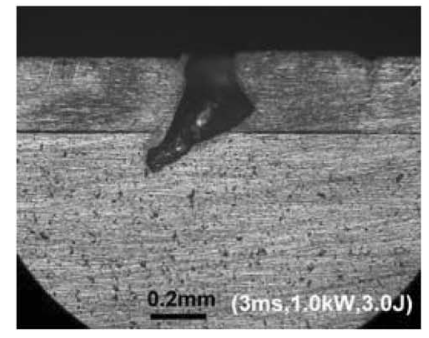

(a)

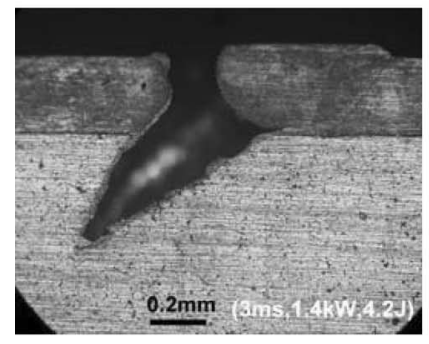

(c)

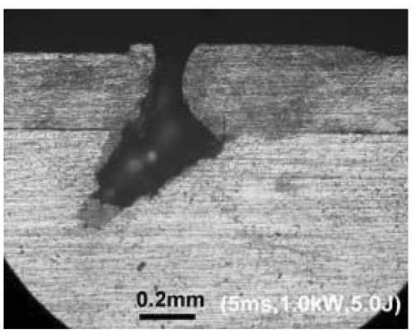

(e)

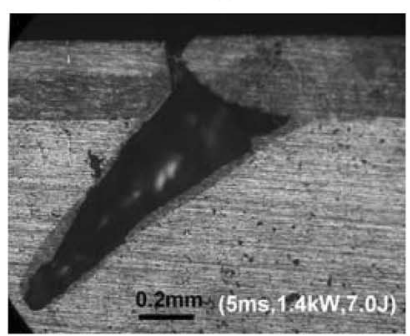

(g)

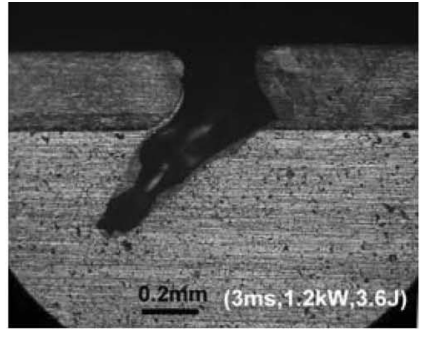

(b)

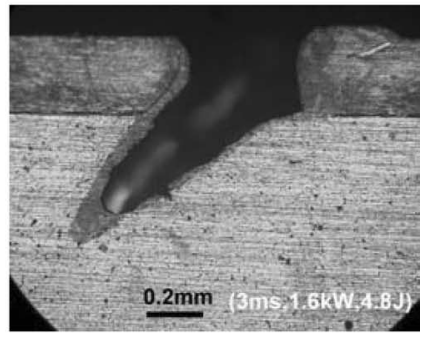

(d)

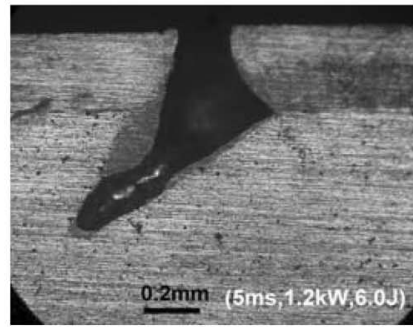

(f)

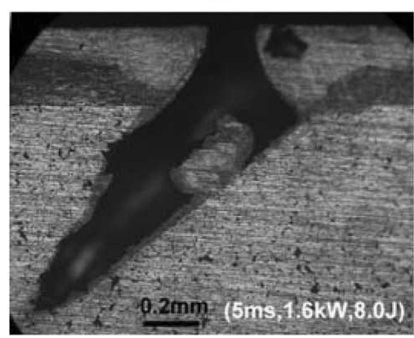

(h)
Fig. 9. Welding joints of DC SS316L (bottom) and SS304L (top). Data in parentheses are pulse duration (millisecond), power (kilowatt), and laser energy (joule).

and lap-fillet joints are measured by a push test. MIM SS316L, MIM Invar, and $100 \%$ density SS316 L are welded to SS304L as shown in Fig. 10. The strengths of MIM 316L/304L joints with three joint geometries are summarized in Table I. Lap joints need additional laser power and energy to penetrate the upper metal part to joint with the lower metal part, as shown in Fig. 10(b). To accomplish strong lap joint strength of more than $15 \mathrm{~kg}$, a laser power of at least $1.2 \mathrm{~kW}$ is necessary. However, this leads to the hole formation and results in more PWS. For fillet joints, less energy is required to achieve proper joint strength, but metal injection from upper metal parts reduces the welding strength and makes the joint unstable when the laser power exceeds $1.2 \mathrm{~kW}$. In addition, the fillet joints are prone to welding cracks along the interface between the two welded parts. The lap-fillet joint, extracting advantages from lap joints and fillet joints, 


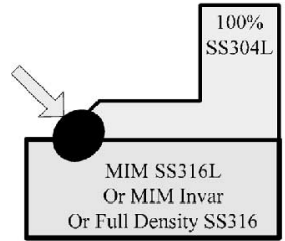

(a)

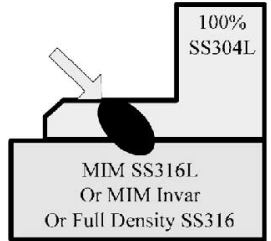

(b)

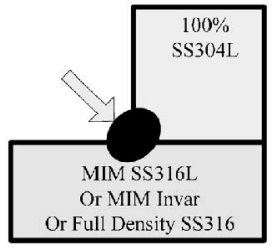

(c)
Fig. 10. Schematic joint geometries for laser welding. (a) Lap-fillet joint. (b) Lap joint. (c) Fillet joint. Arrows indicate the welding spot.

TABLE I

JOINT STRENGTHS (KILOGRAM) OF LAP JOINT, FILLET JOINT, AND LAP-FILLET JoINT With VARIOUS WELDING PARAMETERS. THE DEVIATION OF JOINT STRENGTH IS LESS THAN 10\%

\begin{tabular}{|c|c|c|c|c|c|c|c|c|c|c|c|c|c|c|c|}
\hline \multirow{2}{*}{ Laser Power } & \multicolumn{5}{|c|}{ Lap Joint } & \multicolumn{5}{|c|}{ Fillet joint } & \multicolumn{5}{|c|}{ Lap-fillet Joint } \\
\hline & $2 \mathrm{~ms}$ & $3 \mathrm{~ms}$ & $4 \mathrm{~ms}$ & $5 \mathrm{~ms}$ & $6 \mathrm{~ms}$ & $2 \mathrm{~ms}$ & $3 \mathrm{~ms}$ & $4 \mathrm{~ms}$ & $5 \mathrm{~ms}$ & $6 \mathrm{~ms}$ & $2 \mathrm{~ms}$ & $3 \mathrm{~ms}$ & $4 \mathrm{~ms}$ & $5 \mathrm{~ms}$ & $6 \mathrm{~ms}$ \\
\hline $0.6 \mathrm{kw}$ & $\mathrm{NJ}^{*}$ & $\mathrm{NJ}$ & $\mathrm{NJ}$ & NJ & $\overline{\mathrm{NJ}}$ & | 6.08 & 11.2 & 15.1 & 18.3 & 22.7 & 11.3 & 16.3 & 20.5 & 24.5 & 27.8 \\
\hline $0.8 \mathrm{kw}$ & NJ & $\mathrm{NJ}$ & $\mathrm{NJ}$ & NJ & 2.1 & 10.5 & 15.9 & 20.3 & 24.8 & 27.7 & 13 & 21.3 & 25.5 & 29.5 & 32.5 \\
\hline $1.0 \mathrm{kw}$ & $\mathrm{NJ}$ & 3.1 & 7.7 & 13.7 & 17.8 & 13.8 & 18.8 & 22.2 & 27.5 & 31 & 16.8 & 25.4 & 30.5 & 36 & 39.4 \\
\hline $1.2 \mathrm{kw}$ & 0.9 & 12.3 & 18.2 & 23.7 & 29.7 & $\mathrm{MI}^{\#}$ & MI & MI & MI & MI & 20.6 & 28.5 & 35.6 & 39.9 & 43.3 \\
\hline $1.4 \mathrm{kw}$ & 5.9 & 15.0 & 23.0 & 30.3 & 37.4 & MI & MI & MI & MI & MI & 23.7 & 32.9 & \begin{tabular}{|l|l|}
39.7 \\
\end{tabular} & 45.1 & 49.3 \\
\hline $1.6 \mathrm{kw}$ & 10.8 & 21.2 & 28.6 & 38.9 & 47.9 & MI & MI & MI & MI & MI & MI & MI & MI & MI & MI \\
\hline
\end{tabular}

* No joint is formed. \# Unstable joint caused by metal injection.

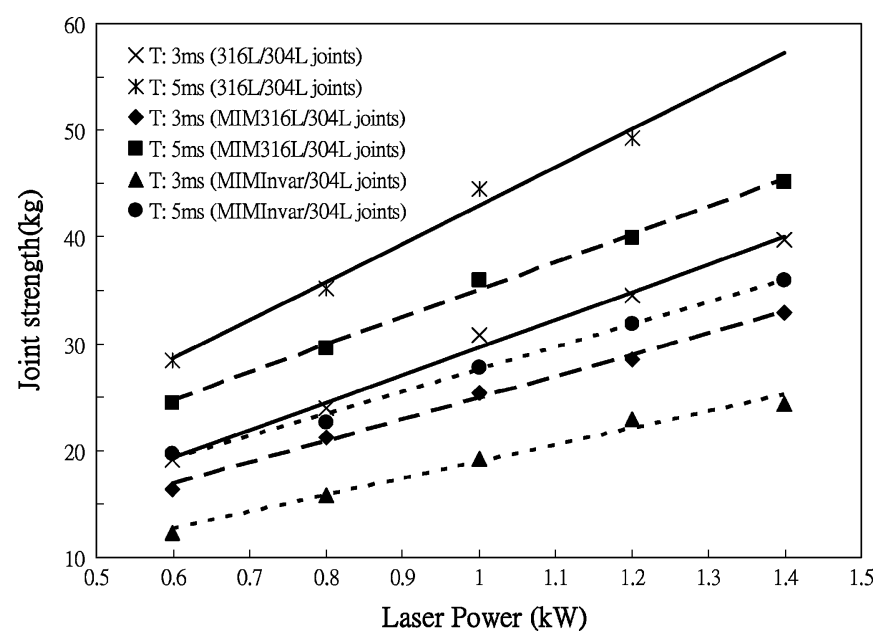

Fig. 11. Strengths of 316L/304L, MIM 316L/304L, and MIM Invar/304L joints as a function of laser power with various pulse durations $T$.

is the best choice for the welding joint. It provides high joint strength to laser power ratio without metal injection and welding cracks.

Fig. 11 shows the strengths of MIM 316L/304L, MIM Invar/304L, and 316L/304L joints by using lap-fillet joints as a function of the laser power and pulse duration. The joint strength increases linearly with laser power in accordance with the penetration depth and decreases as the density decreases. Although the penetration depth of MIM SS316L is larger than that of $100 \%$ density SS316L, as shown in Fig. 7, the strength of MIM $316 \mathrm{~L} / 304 \mathrm{~L}$ joint is less than that of $316 \mathrm{~L} / 304 \mathrm{~L}$ joint. The reason is that mechanical strength of $100 \%$ density SS316L is larger than MIM SS316L. The same reason explains why the strength

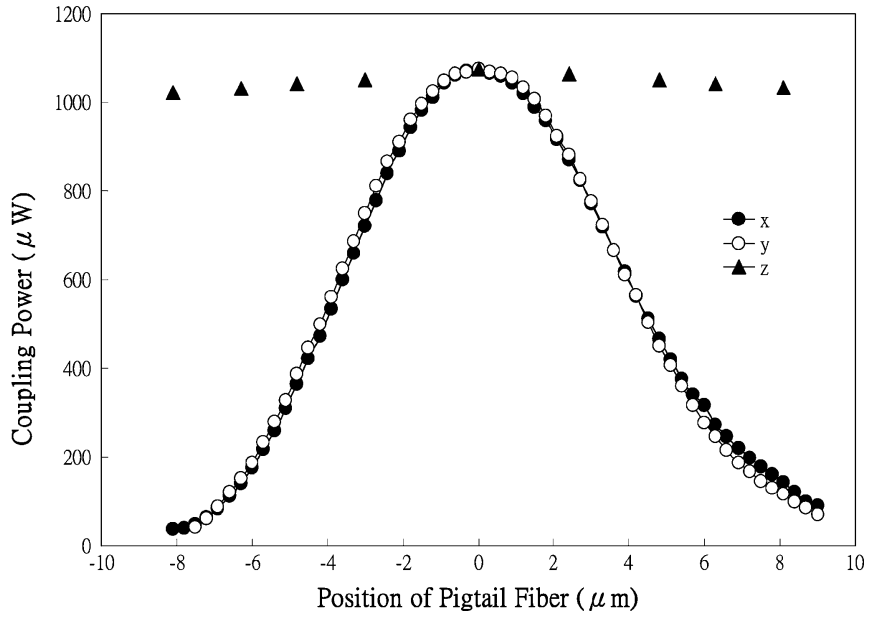

Fig. 12. Coupling power as a function of $x, y$, and $z$ orientations.

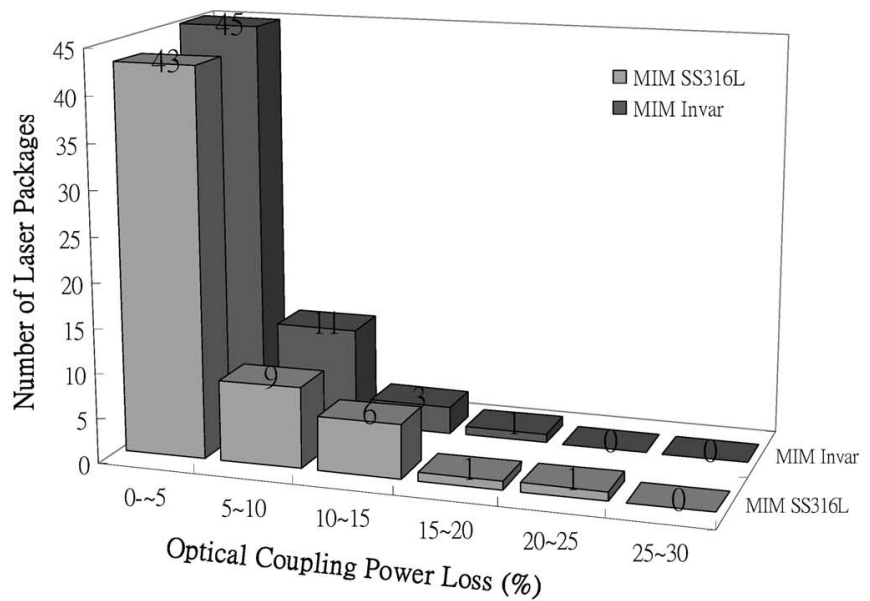

(a)

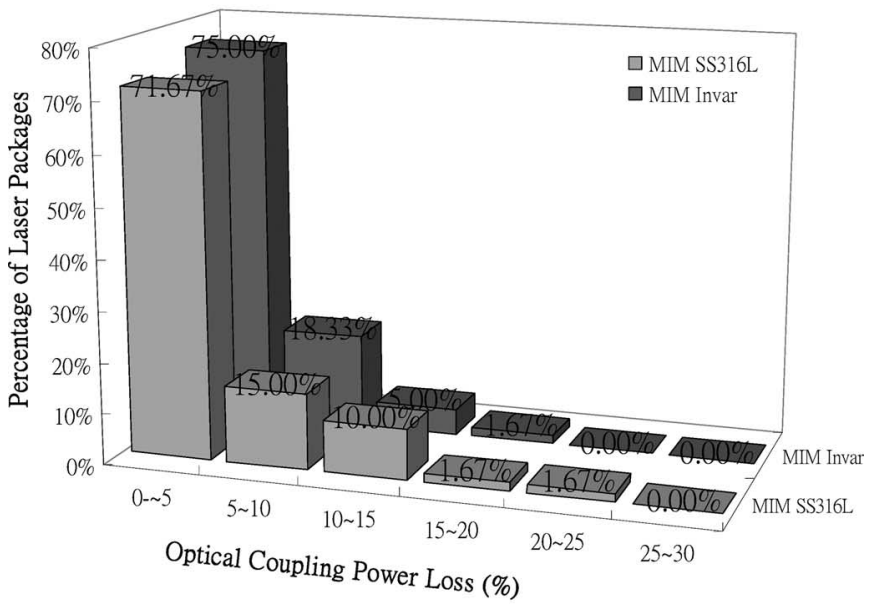

(b)

Fig. 13. Distribution of the coupling power loss due to PWS.

of the MIM 316L/304L joint is greater than that of the MIM Invar/304L joint. By optimizing welding parameters, the lap-fillet joint with laser power and pulse duration of $0.8 \mathrm{~kW}$ and $3 \mathrm{~ms}$, respectively, is selected for the laser welding process. The lapfillet joints without any defects are achieved, and the strengths 
TABLE II

TRACKING ERRoR (DeCIBEL) OF THE LASER MODULeS With MIM SS316L MATERIAL AS THE LASER HOUSING

\begin{tabular}{|c|c|c|c|c|c|c|c|c|c|}
\hline \multirow{2}{*}{ Temperature } & \multicolumn{7}{|c|}{ Module Number } & Average \\
& 1 & 2 & 3 & 4 & 5 & 6 & 7 & 8 & Deviation* \\
\hline$-40^{\circ} \mathrm{C}$ & -0.415 & -0.424 & -0.160 & -0.427 & -0.015 & -0.285 & -0.349 & -0.256 & 0.292 \\
\hline $0^{\circ} \mathrm{C}$ & -0.230 & -0.285 & -0.063 & -0.236 & 0.112 & -0.225 & -0.196 & -0.148 & 0.187 \\
\hline $25^{\circ} \mathrm{C}$ & 0.000 & 0.000 & 0.000 & 0.000 & 0.000 & 0.000 & 0.000 & 0.000 & 0.000 \\
\hline $70^{\circ} \mathrm{C}$ & 0.257 & 0.224 & 0.228 & 0.343 & -0.327 & -0.116 & 0.259 & -0.268 & 0.253 \\
\hline $85^{\circ} \mathrm{C}$ & 0.306 & 0.311 & 0.272 & 0.366 & -0.578 & -0.243 & 0.305 & -0.356 & 0.342 \\
\hline $\begin{array}{l}\text { Maximum } \\
\text { Deviation\# }\end{array}$ & 0.721 & 0.735 & 0.433 & 0.793 & 0.691 & 0.285 & 0.654 & 0.356 & \\
\hline
\end{tabular}

TABLE III

TRACKING ERROR (DECIBEL) OF THE LASER MODULES WITH MIM INVAR MATERIAL AS THE LASER HOUSING

\begin{tabular}{|c|c|c|c|c|c|c|c|c|c|}
\hline \multirow{2}{*}{ Temperature } & \multicolumn{7}{|c|}{ Module Number } & Average \\
& 1 & 2 & 3 & 4 & 5 & 6 & 7 & 8 & Deviation \\
\hline$-40^{\circ} \mathrm{C}$ & -0.222 & -0.286 & 0.035 & -0.273 & 0.236 & -0.073 & 0.121 & -0.319 & 0.196 \\
\hline $0^{\circ} \mathrm{C}$ & 0.042 & -0.152 & 0.085 & -0.144 & 0.106 & -0.024 & 0.103 & -0.248 & 0.113 \\
\hline $25^{\circ} \mathrm{C}$ & 0.000 & 0.000 & 0.000 & 0.000 & 0.000 & 0.000 & 0.000 & 0.000 & 0.000 \\
\hline $70^{\circ} \mathrm{C}$ & 0.115 & 0.084 & -0.079 & -0.152 & 0.112 & -0.114 & 0.187 & -0.198 & 0.130 \\
\hline $85^{\circ} \mathrm{C}$ & 0.171 & 0.134 & -0.113 & -0.181 & 0.271 & -0.179 & 0.222 & -0.257 & 0.191 \\
\hline $\begin{array}{l}\text { Maximum } \\
\text { Deviation }\end{array}$ & 0.394 & 0.419 & 0.198 & 0.273 & 0.271 & 0.179 & 0.222 & 0.319 & \\
\hline
\end{tabular}

of both MIM 316L/304L and MIM Invar/304L joints are more than $15 \mathrm{~kg}$, which ensures long-term reliability.

\section{E. PWS}

PWS is the misalignment between two welded parts, and a few micrometers of the alignment shift can induce up to $50 \%$ coupling power loss. Therefore, a detailed understanding of the PWS mechanism is the key to eliminating or minimizing the PWS-induced misalignment. The PWS mechanisms may be intrinsic and/or extrinsic. The intrinsic PWS is generated by rapid solidification of the welded region and the associated material shrinkage. In addition, the inherent porosity of MIM steel contributes additional PWS. Under optimal welding condition, elimination of inherent pores results in more shrinkage of the welded region, which gives rise to more coupling power loss. The shrinkage force is so great that no mechanical structure, such as the device gripper, can counteract the shrinkage shift [5]. The extrinsic PWS is resulted from laser parameters including laser power, laser energy, and pulse duration, energy balance of laser beams, the incident angle of laser beams, joint geometry, welding positions, welding process, machining tolerance of components, roughness of two welded surfaces, and device gripper design of laser welding systems.

The misalignment due to the extrinsic PWS can be minimized or eliminated by optimizing welding condition, but the intrinsic PWS cannot be avoided. Laser hammering (LH) is a well-known method to correct the intrinsic PWS by using additional laser

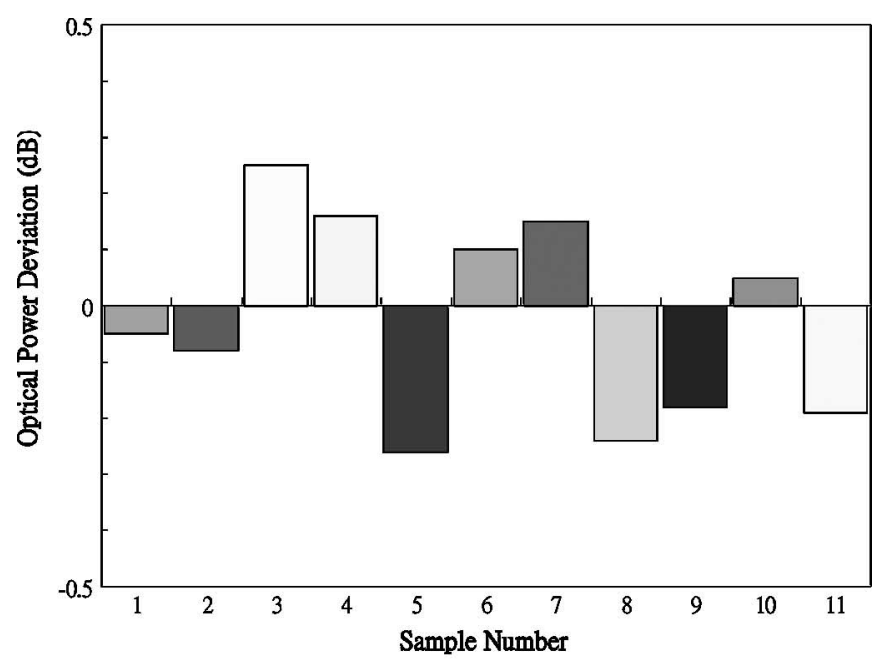

(a)

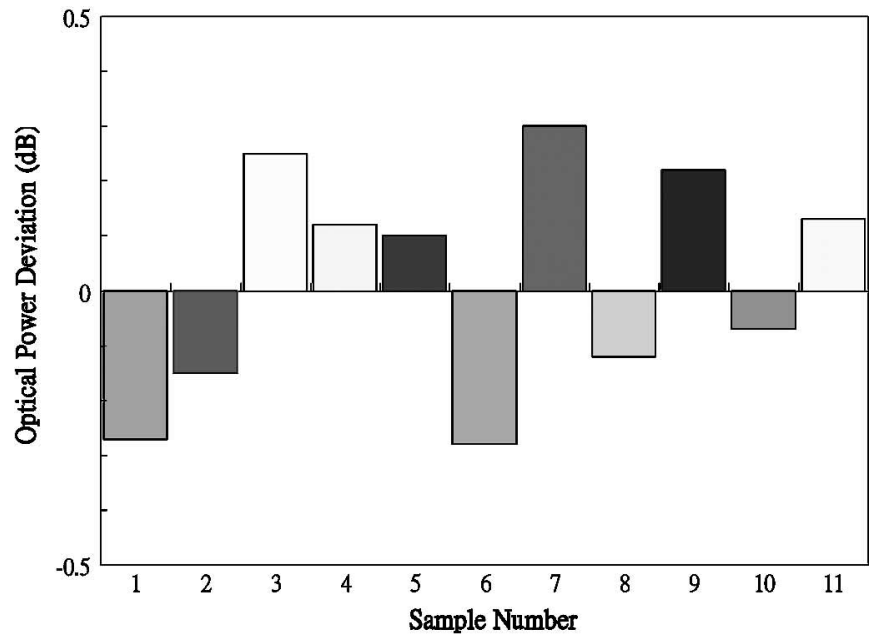

(b)

Fig. 14. Optical power deviation after mechanical shock test. The laser modules are subject to five shock pulses for each of the orientations $x, y$, and $z$. The peak acceleration of the pulse is $1500 \mathrm{~g}$ and the pulse duration is $0.5 \mathrm{~ms}$. The pass/fail criterion is $0.5 \mathrm{~dB}$ maximum change in optical coupling power. (a) MIM SS316L. (b) MIM Invar.

welding spots to push the fiber back to the maximum coupling position [4], [7]. The LH process has already been proven to be effective to reduce PWS. However, the LH method increases the cycle time of laser welding process and creates asymmetrical laser welding spots resulting in long-term reliability issue. Thus, how inherent porosity of MIM steel affects the intrinsic PWS is the key to determining the yield of the laser module manufacturing.

The magnitude of PWS is at the micrometer level, hence, the direct measurement is very difficult. The PWS in this paper is estimated with coupling power loss. Before welding, the laser and single-mode fiber are precisely aligned to reach the maximum coupling power. After welding, solidification shrinkage of the welding pool gives rise to the transverse movement that results in coupling power loss. The coupling power loss and the associated transverse movement are used to determine the PWS. Fig. 12 shows the optical coupling profile of TO-Can laser packages with a built-in $1.5-\mathrm{mm}$ ball lens. In order to investigate 


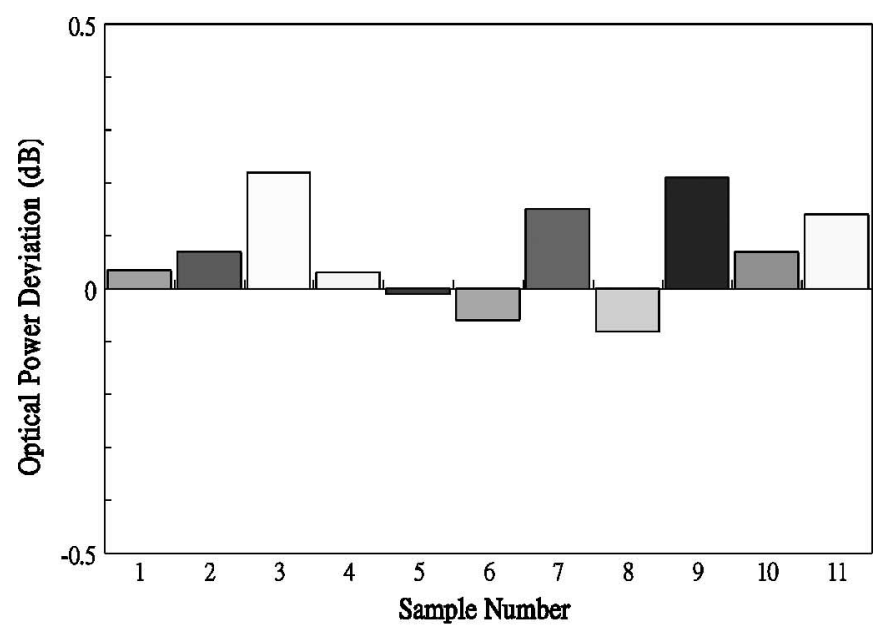

(a)

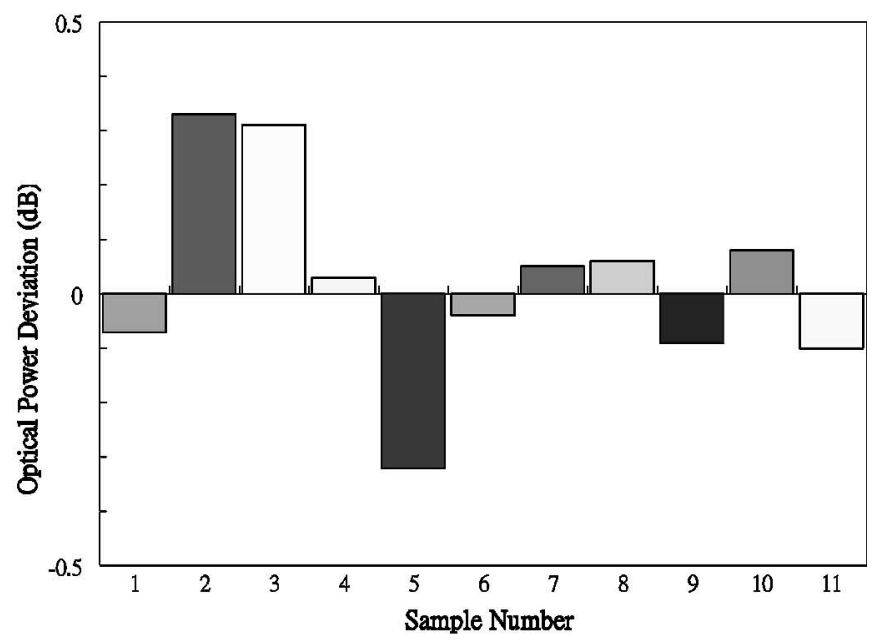

(b)

Fig. 15. Optical power deviation after vibration test. The frequency ranges from 20 to $2000 \mathrm{~Hz}$ and return to $20 \mathrm{~Hz}$, and the cycle time is not less than $4 \mathrm{~min}$. This cycle is performed four times for each of orientations $x, y$, and $z$. The pass/fail criterion is $0.5 \mathrm{~dB}$ maximum change in optical coupling power. (a) MIM SS316L. (b) MIM Invar.

the intrinsic PWS, the laser welding conditions are optimized to minimize/eliminate the extrinsic PWS as mentioned in Sections II-A, II-B, and III-D. The lap-fillet joint with laser power and pulse duration of $0.8 \mathrm{~kW}$ and $3 \mathrm{~ms}$, respectively, is chosen as the welding geometry for the assembly of the laser part and the pigtail part. The SS304L ferrule and the pigtail housing made of SS304L are welded with the laser power and the pulse duration of $1.4 \mathrm{~kW}$ and $2.5 \mathrm{~ms}$, respectively. Fig. 13 shows the distribution of the coupling loss due to the PWS from 60 pieces of the welded laser modules with the laser housing made of MIM SS316L and MIM Invar. The MIM Invar material with low CTE can reduce the material shrinkage of the welded region and the associated intrinsic PWS. However, the results do not present this advantage clearly. The reason is that the PWS is small and is influenced by various factors. Therefore, it is extremely difficult to identify the respective contribution of each factor. The coupling loss of over $95 \%$ of specimens in this study is less than $15 \%$, which corresponds to the PWS of less than $2 \mu \mathrm{m}$. Even

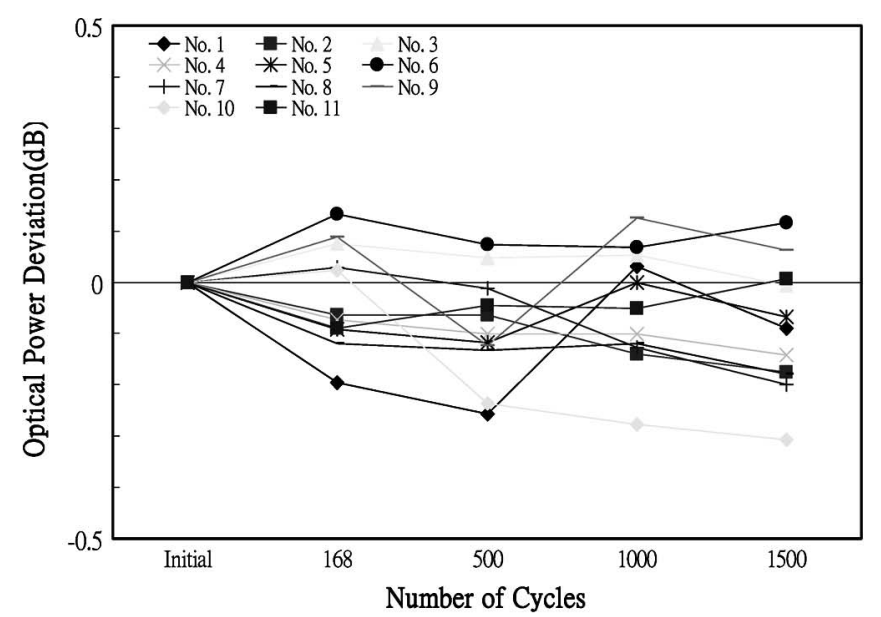

(a)

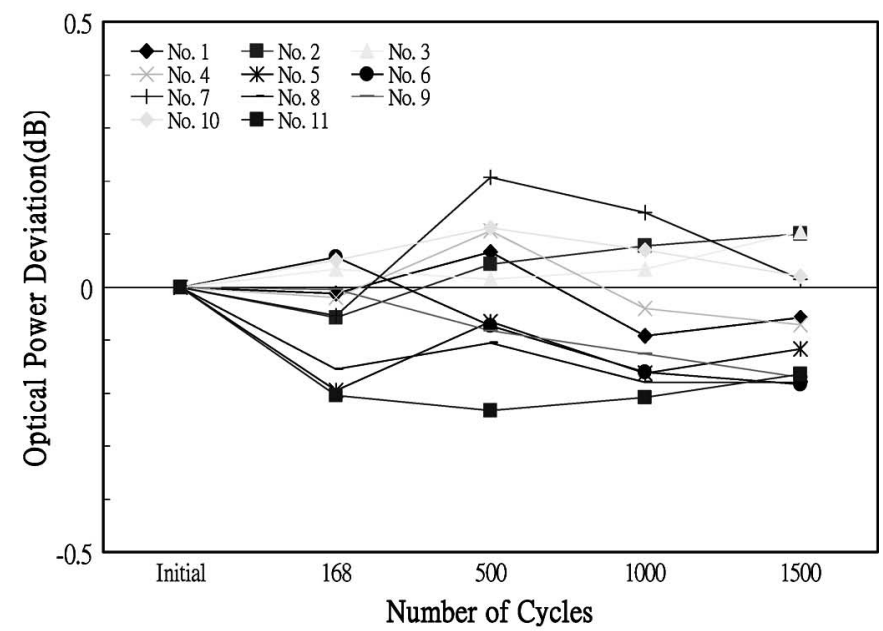

(b)

Fig. 16. Optical power deviation with numbers of temperature cycling test The temperature changes from $-40^{\circ} \mathrm{C}$ to $85^{\circ} \mathrm{C}$. The ramp rate is more than $10^{\circ} \mathrm{C} / \mathrm{min}$ and the dwell time is $10 \mathrm{~min}$ at $85^{\circ} \mathrm{C}$ and $-40^{\circ} \mathrm{C}$. The cycle time is within $40 \mathrm{~min}$. The pass/fail criterion is $0.5 \mathrm{~dB}$ maximum change in optical coupling power after 500 cycles. (a) MIM SS316L. (b) MIM Invar.

with MIM steel, of which more PWS is induced during the laser welding process, it is still controlled to less than $2 \mu \mathrm{m}$.

\section{F. Tracking Error}

The box-type optoelectronic packages, which are used in high-performance lightwave communication systems, incorporate thermoelectric coolers and thermistors to maintain the laser diode operation at optimum temperature so that laser operation can be obtained under extremes of ambient temperature. The optoelectronic packages for low-cost market, including the cylindrical-type packages, bidirectional packages, and tripledirectional packages, are operated without temperature controller due to the cost-effectiveness issue. The laser diode is mounted in the hermetic TO-Can package. The TO-Can package also contains a photodiode for monitoring and controlling the laser diode at the constant output power and extinction ratio as shown in Fig. 2(c). Using the monitor photodiode can compensate for the optical power deviation of the laser diode 


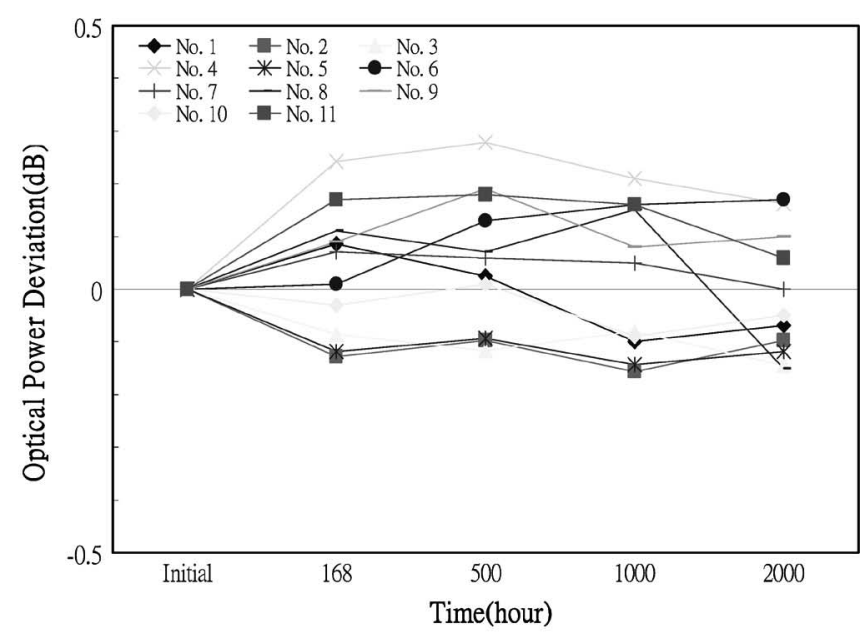

(a)

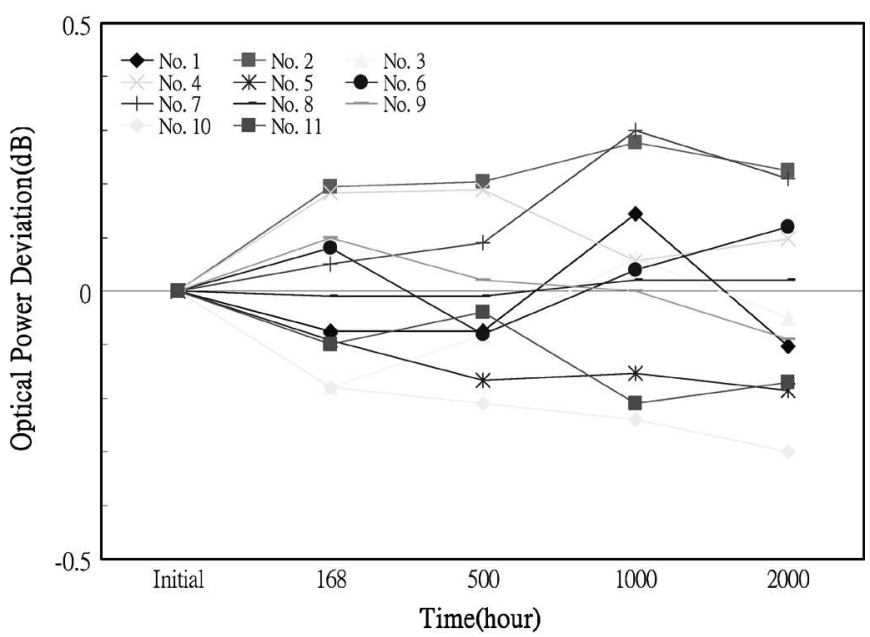

(b)

Fig. 17. Optical power deviation with time of high temperature storage test. The laser modules are tested at $85^{\circ} \mathrm{C}$. Pass/fail criteria are $0.5 \mathrm{~dB}$ maximum change in optical coupling power after $2000 \mathrm{~h}$. (a) MIM SS316L. (b) MIM Invar.

operated at different ambient temperatures, but it cannot compensate the coupling power loss caused by the alignment change due to the CTE mismatch of individual parts in laser packages at various operating temperatures.

The front-to-rear tracking error is related to the alignment change due to laser packages operated at various ambient temperatures [14]. The rear-facet monitor photodiode is set to a constant that is corresponding to the associated output power at nominal operating temperature from the front facet of laser diode at the pigtail of the laser package. The front-to-rear tracking error is calculated by the equation given below when varying the temperature

$$
\text { Tracking error }(\mathrm{dB})=10 \times \log \frac{P_{\mathrm{o}}(\mathrm{T})}{P_{\mathrm{o}}\left(25^{\circ} \mathrm{C}\right)}
$$

where $P_{\mathrm{o}}\left(25^{\circ} \mathrm{C}\right)$ is the optical output power at $25^{\circ} \mathrm{C}$, and $P_{\mathrm{o}}(T)$ is the optical output power at $T$. Tables II and III show the tracking error of the welded laser modules with the laser housing made of MIM SS316L and MIM Invar, respectively. Laser modules with low CTE MIM Invar materials present better

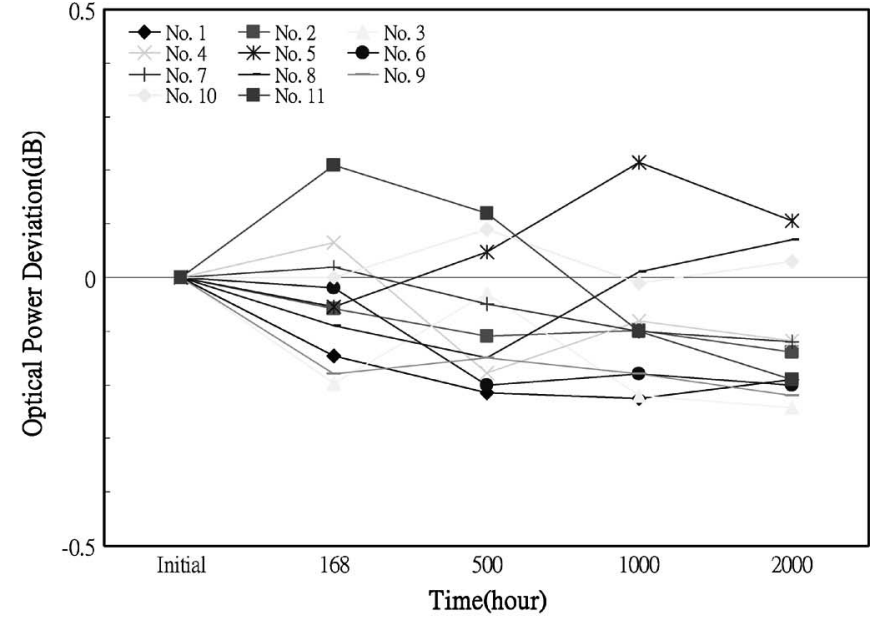

(a)

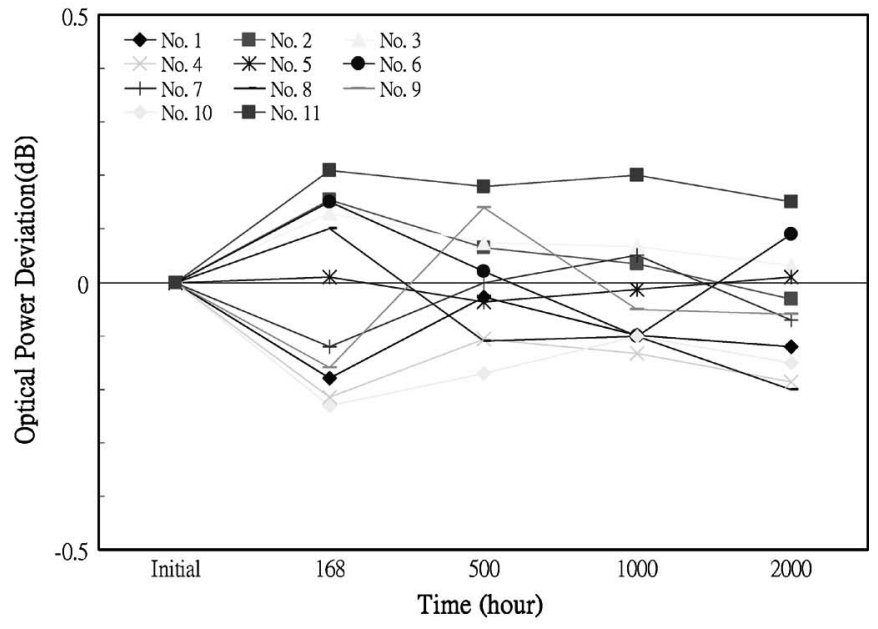

(b)

Fig. 18. Optical power deviation with time of low temperature storage test. The laser modules are tested at $-40^{\circ} \mathrm{C}$. Pass/fail criteria are $0.5 \mathrm{~dB}$ maximum change in optical coupling power after $2000 \mathrm{~h}$. (a) MIM SS316L. (b) MIM Invar.

performance of tracking error. This better performance of tracking error by using low CTE material is helpful to bidirectional and triple-directional optoelectronic packages. The bodies of bidirectional and triple-directional optoelectronic packages possess asymmetric shapes and are assembled with WDM filters, laser diode and photodiode with TO-Can packages, and other metal parts as shown in Fig. 1(c). For cylindrical-type packages, symmetric thermal expansion and contraction can counteract the misalignment due to the CTE mismatch. However, the asymmetric shapes of bidirectional and triple-directional optoelectronic packages give rise to asymmetric thermal expansion and contraction, resulting in more tracking error. Using MIM Invar with low CTE as construction material of asymmetric optoelectronic packages can minimize the tracking error, which is an important issue for bidirectional and triple-directional optoelectronic packages.

\section{RELIABILITY TESTS}

The reliable performance of the optoelectronic packages depends on the ability to maintain the optimum alignment position 
between the laser and the fiber in the operating environment. The reliability tests of the laser modules consist of 30 different tests grouped into mechanical (mechanical shock, vibration, thermal shock, solderability, and fiber pull), endurance (accelerated aging, high-temperature storage, low temperature, temperature cycling, damp heat, and cyclic moisture resistance), and special tests (internal moisture, ESD threshold) categories based on Telcordia GR-468-CORE and MIL-STD-883E specifications [14]. To ensure long-term reliability, the laser modules are subjected to temperature cycling test, low-temperature storage test, and high-temperature storage test. Mechanical shock and vibration tests are selected to test the stability of the laser modules. Eleven laser modules with MIM SS316L and MIM Invar materials used for the laser housing, which are fabricated for investigating PWS and tracking error, are tested for each of test items. Under these tests, no failures are observed as shown in Figs. 14-18. The reliability test data demonstrate that the laser modules using MIM steel as construction housing, and those that are without any defects in the welding joints are stable and reliable.

\section{CONCLUSION}

In summary, we have successfully presented a cost-effective method of fabricating metal parts by using MIM steel. The MIM method not only reduces the number of metal parts in the laser module but also greatly reduces the cost. In addition, the advantage of applicability of the MIM method to several materials can introduce SS316L, Kovar, and Invar material, which have characteristic of better property but difficult machining, into optoelectronic packages used in low-cost lightwave communication systems. Moreover, employment of metal injection molding can give optoelectronic module designer more design flexibility due to the advantage of shape complexity and make low-cost triple-directional optoelectronic module realizable. The following conclusions can be drawn from the study presented in this paper.

i) For the welding joint of DC steel with high content of continuous porosity, gas expansion of a serious nature gives rise to metal injection resulting in weak and unstable joints.

ii) The laser power is one of the most important parameters to control the defect formation of MIM steel during laser welding. The defect-free welding joints of MIM steel can be attained by using laser power of less than $1.0 \mathrm{~kW}$.

iii) By optimizing welding parameters, the lap-fillet joint with a laser power and a pulse duration of $0.8 \mathrm{~kW}$ and $3 \mathrm{~ms}$, respectively, is selected. The strength of the defect-free joint with MIM steel is larger than $15 \mathrm{~kg}$.

iv) Although elimination of inherent porosity in MIM steel under optimum welding condition can give rise to additional PWS, the PWS is still controlled to less than $2 \mu \mathrm{m}$ resulting in optical coupling loss of less than $15 \%$.

v) Using MIM Invar with low CTE as construction material of asymmetric optoelectronic packages can minimize the tracking error, which is an important issue for bidirectional and triple-directional optoelectronic packages. vi) The reliability tests data demonstrate that the laser modules using MIM steel as construction housing and without any defects in the welding joints are stable and reliable.

\section{ACKNOWLEDGMENT}

The authors would like to thank Dr. S.-C. Wang (Fiberxon, Inc.) for useful discussions.

\section{REFERENCES}

[1] D. S. Alles, "Trends in laser packaging," in Proc. 40th Electron. Comp. Technol. Conf., 1990, pp. 185-192.

[2] M. R. Matthews, B. M. Macdonald, and K. R. Preston, "Optical components-The new challenge in packaging," IEEE Trans. Compon., Hybrids, Manuf. Technol., vol. 13, no. 4, pp. 798-806, Dec. 1990.

[3] A. A. Hollander and K. J. Watkins, "The art and science of optoelectronic joining," Photonics Spectra, pp. 110-114, Oct. 1993.

[4] B. Valk, R. Battig, and O. Anthamatren, "Laser welding for fiber pigtailing with long-term stability and submicron accuracy," Opt. Eng., vol. 34, no. 9, pp. 2675-2682, 1995.

[5] M. K. Song, S. G. Kang, N. Hwang, H. T. Lee, S. S. Park, and K. E. Pyun, "Laser weldability analysis of high-speed optical transmission device packaging," IEEE Trans. Compon., Packag., Manuf. Technol. A, vol. 19 no. 4, pp. 758-763, Nov. 1996.

[6] W. H. Cheng, W. H. Wang, and J. C. Chen, "Defect formation mechanisms in laser welding techniques for semiconductor laser packaging," IEEE Trans. Compon., Hybrids, Manuf. Technol. B, vol. 20, no. 4, pp. 396-402, Nov. 1997.

[7] Y. C. Hsu, Y. C. Tsai, Y. L. Ho, M. T. Sheen, J. H. Kuang, and W. H. Cheng, "A novel alignment shift measurement and correction technique in laserwelded laser module packaging," J. Lightw. Technol., vol. 23, no. 2 , pp. 486-494, Feb. 2005.

[8] W. H. Cheng, M. T. Sheen, C. M. Cheng, and Y. T. Tseng, "An optimum approach for reduction of fiber alignment shift of fiber-solder-ferrule joints in laser module packaging," J. Lightw. Technol., vol. 22, no. 2, pp. 589 594, Feb. 2004.

[9] W. S. Chang and S. J. Na, "Thermomechanical analyses of laser precision joint for optoelectronic components," J. Trans. Adv. Packag., vol. 26 , no. 2, pp. 349-358, Jun. 2003.

[10] Y. Lin, W. Liu, and F. G. Shi, "Laser welding induced alignment distortion in butterfly laser module packages: Effect of welding sequence," J. Trans. Adv. Packag., vol. 25, no. 1, pp. 73-78, Feb. 2002.

[11] J. H. Kuang, M. T. Sheen, S. C. Wang, G. L. Wang, and W. H. Cheng, "Post-weld-shift in dual-in-line laser package," J. Trans. Adv. Packag., vol. 24, no. 1, pp. 81-85, Feb. 2001.

[12] R. M. German, Powder Metallurgy Science. Princeton, NJ: Metal Powder Industries Federation, 1984.

[13] R. M. German and A. Bose, Injection Molding of Metals and Ceramics Princeton, NJ: Metal Powder Industries Federation, 1997

[14] Generic Reliability Assurance Requirements for Optoelectronic Device Used in Telecommunications System, Bellcore, GR-468-CORE, Dec. 1998.

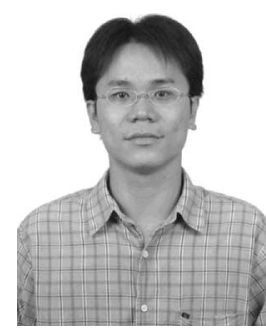

Chun-Ting Lin received the B.S. and M.S. degrees in materials science and engineering from National Tsing Huang University, Hsinchu, Taiwan, R.O.C., in 1997 and 2001, respectively. He is currently working toward the Ph.D. degree in electro-optical engineering at the National Chiao Tung University, Hsinchu, Taiwan, R.O.C.

From 1999 to 2001, he was an Engineer at Front Edge Technology, Inc., Baldwin Park, CA, where he was engaged in research on a micro battery (thin film battery) designed for highly space-limited micro devices. From 2001 to 2004, he was an Optoelectronic Package Deputy Manager with Ritek Corporation, Taiwan, R.O.C., where he was engaged in research on the design and fabrication of optoelectronic packages for high-speed and low-cost lightwave communication. His current research interests include optoelectronic packages, optical microwave-and millimeter-wave signals and data formats of optical communication. 
Bi-Shiou Chiou received the B.S. degree in nuclear engineering and the M.S. degree in health physics from the National Tsing Huang University, Hsinchu, Taiwan, R.O.C., in 1975 and 1977, respectively, and the Ph.D. degree in materials science and engineering from Purdue University, West Lafayette, IN, in 1981.

She is currently a Professor of Electronics Engineering at the National Chiao Tung University, Hsinchu, Taiwan, R.O.C. Her research interests include electronic packaging, electronic ceramics, thick and thin film technology, and optoelectronic packaging.
Sien Chi received the B.S.E.E. degree from the National Taiwan University, Taipei, Taiwan, R.O.C., and the M.S.E.E. degree from National Chiao Tung University, Hsinchu, Taiwan, R.O.C, in 1959 and 1961, respectively. He received the Ph.D. degree in electro-physics from the Polytechnic Institute, Brooklyn, NY, in 1971.

From 1971 to 2004, he was a Professor at the National Chiao Tung University. He is currently a Chair Professor at Yuan Ze University, Chung-Li, Taiwan, R.O.C. His current research interests include optical fiber communications, optical solitons, optical modulation formats, and optical fiber amplifiers. From 1998 to 2001, he was the Vice President of the National Chiao Tung University. Since 1996, he has been the Chair Professor of the Foundation for Advancement of Outstanding Scholarship.

Dr. Chi is a Fellow of both the Optical Society of America (OSA) and the Photonics Society of Chinese Americans (PSCA). In 1992, he was the Symposium Chair of the International Symposium on Optoelectronics in Computers, Communications and Control, which was co-organized by National Chiao Tung University and the SPIE. 